\title{
La recepción de la teoría celular en Gaceta Médica de México en el siglo XIX
}

\author{
Andrés Aranda-Cruzalta
}

Universidad Nacional Autónoma de México, Facultad de Medicina, Departamento de Historia y Filosofía de la Medicina, Ciudad de México, México

\section{Resumen}

En el siglo XIX se llevó a cabo en América una serie de movimientos independentistas en contra del orden establecido por las potencias europeas dominantes. Esto dio lugar al concepto de "lo nacional" y "lo internacional o extranjero" En forma paralela, en el mundo científico surgió "la teoría celular", basada en la idea de que los seres vivos, tanto vegetales como animales, estaban constituidos por unidades anatomofuncionales, las células, en las que se realizan las funciones vitales. Esta teoría fue encabezada por el botánico Mathias Jacob Schleiden y por el zoólogo Theodor Schwann. Gaceta Médica de México, fue fundada en 1864, cuando la teoría celular se encontraba en su madurez. El propósito de este escrito es documentar cómo fue recibida y divulgada esta teoría en México a través de los artículos publicados en Gaceta Médica de México.

PALABRAS CLAVE: Historia de la medicina; Teoría celular; Difusión y divulgación de la ciencia.

\begin{abstract}
In the 18th century, a series of pro-independence movements took place in America against the order established by European dominant powers. This gave way to the concept of "national" and "international or foreign" affairs. In parallel, "the cell theory" emerged in the scientific world, based on the idea that living beings, both plants and animals, were constituted of anatomo-functional units, the cells, where vital functions take place. This theory was headed by the botanist Mathias Jacob Schleiden and zoologist Theodor Schwann. Gaceta Médica de México was founded in 1864, when the cell theory was already mature. The purpose of this manuscript is to document how this theory was received and disseminated in Mexico through articles published in Gaceta Médica de México.
\end{abstract}

KEY WORDS: History of medicine. Cell theory. Diffusion and dissemination of science.

\section{Introducción}

Los estudiosos de la historia de la Academia Nacional de Medicina y su órgano de difusión, la Gaceta Médica de México, han mostrado que a lo largo del siglo XIX la finalidad de los editores de la Gaceta se desplazó de la intención inicial de "[...] poner a la vista de cada uno de sus miembros, en un periódico bi-mensual, los frutos que haya podido reunir en su seno $[\ldots],{ }^{1,2}$ hacia miras más amplias en las que, además, de difundir los trabajos entre los miembros de la corporación se buscaba dar a conocer, preservar y ampliar un conjunto de observaciones, cuyas particularidades se consideraron de utilidad para quienes ejercían la medicina en México, a la vez que se mantenía un interés abierto hacía lo que ocurría en otras latitudes, particularmente en la medicina europea, que a la sazón dominaba el panorama mundial.

Las tensiones entre lo nacional y lo internacional, que se habían intensificado a partir de la Independencia, quedaban circunscritas por los editores de la
Correspondencia:

Andrés Aranda-Cruzalta

E-mail: andresaranda@ comunidad.unam.mx
Fecha de recepción: 16-01-2017

Fecha de aceptación: 20-10-2017

DOI://dx.doi.org/10.24875/GMM.17003193
Gac Med Mex. 2018;154:391-397

Disponible en PubMed www.gacetamedicademexico.com 
Gaceta a identificar lo extranjero con el conocimiento general de la medicina, y lo nacional con los resultados obtenidos de la adecuación de aquel a las peculiaridades observables en México, inscribiendo tal diferencia en términos fisiológicos, patológicos, terapéuticos e ideosincrásicos, con lo que quedaban definidas las líneas fundamentales que seguirían alimentando la empresa científica y editorial de la Academia Nacional de Medicina. ${ }^{3}$

Trabajos históricos, realizados desde diferentes corrientes interpretativas, sostienen que durante las décadas siguientes disciplinas como la anatomía patológica, la microbiología, la farmacia y la geografía médica desempeñaron un papel central en el proceso de institucionalización de las ciencias médico-biológicas, pues en torno a ellas se desarrollaron el Instituto Médico Nacional (1888), el Museo Anatomo-patológico (1895), mismo que luego dio origen al Instituto Patológico Nacional (1899), del cual se desprendería unos años más tarde, el Instituto Bacteriológico Nacional (1905). ${ }^{4-6}$

Con base en estos estudios se puede afirmar que, a través de sus sesiones científicas y de su proyecto editorial, la Academia Nacional de Medicina acogió y dio difusión tanto a las ideas de avanzada que estaban revolucionando el pensamiento médico-biológico en el siglo XIX, como a las prácticas que de este se desprendieron. ${ }^{7}$ Lo que parecería razón suficiente para justificar un estudio sobre la recepción de la teoría celular en la Gaceta Médica de México.

Tal justificación sugeriría que el presente trabajo se encamina a seguir la tradición de la historia institucional que, si bien ha sido muy útil, también —como ha señalado Laura Cházaro- ha tenido el inconveniente de crear, desde el presente, divisiones aparentes que conducen al historiador a omitir en el análisis del proceso histórico, el seguimiento y la descripción de la movilidad laboral característica de la élite de investigadores de aquella época, ${ }^{8}$ sin embargo, cabe aclarar que es parte de un proyecto más amplio que busca dar seguimiento a la recepción que tuvo en México la teoría celular, a través del estudio de las publicaciones periódicas, de las tesis y los libros publicados por diversas instancias que fueron conformando el panorama institucional del quehacer científico mexicano a finales del siglo XIX y principios del XX, entre las cuales la Academia Nacional de Medicina desempeñó inicialmente un papel preponderante, por lo que se presenta a continuación el resultado del estudio de los artículos publicados en Gaceta Médica de México, primera fase de esa investigación más amplia.

\section{La teoría celular en la Gaceta Médica de México}

La teoría celular —basada en la idea de que los seres vivos, tanto vegetales como animales, estamos constituidos por unidades anatomofuncionales en las que se realizan las funciones vitales - tomó su primer impulso en Europa en la década de los treinta del siglo XIX, con los trabajos del botánico Matthias Jacob Schleiden y del zoólogo Theodor Schwann.

Transcurrieron alrededor de setenta años desde que aparecieran estos primeros trabajos para que Camilo Golgi y Santiago Ramón y Cajal recibieran el Nobel por sus contribuciones en torno a la histología del sistema nervioso, mismas que explicaban, entre otras cosas, que el sistema nervioso aunque se comportara como un sincitio funcional estaba constituido por un entramado de células estructuralmente separadas, con lo que se corroboraba la base celular de todos los tejidos y órganos y se le daba plena aceptación a dicha teoría.

A lo largo de esas décadas se fueron creando nuevas disciplinas, cuyo sustento teórico se basó en las diversas formulaciones que se hicieron en torno a la teoría celular, así fueron fundándose la citología, la histología y -cuando la teoría se aplicó al campo de la patología, particularmente por mediación de los trabajos de Virchow - la histopatología. ${ }^{9}$

Teniendo en cuenta el panorama anterior, resultaba razonable buscar los canales que permitieron que dicha teoría se introdujera en México en las diversas instituciones médicas, incluida desde luego la Academia Nacional de Medicina, cuya historia corre en paralelo a la del desarrollo teórico de las formulaciones científicas sobre la célula.

Por otro lado, en lo tocante a las universidades, los datos que arrojan algunos análisis previos son más bien escasos, pues estos se reducen a señalar que la primera cátedra de histología en México fue fundada en 1882 en la Escuela Nacional de Medicina y que unos años más tarde volvía de Europa el doctor Lara para fundar una segunda en la Escuela Médico Militar.

De la cátedra de la Escuela Nacional de Medicina se sabe, además, que fue impartida por el doctor Miguel Cordero, quien a la sazón era miembro de la Academia Nacional de Medicina, y que para su enseñanza fueron utilizados el libro de Fort, destinado al conocimiento de la histología normal, y el de Duval, que se empleaba para que los alumnos aprendieran la técnica histológica. Al parecer, dichos textos fueron 
elegidos por su carácter ecléctico, lo que los hizo preferibles por encima de otras obras que se consideraban a la sazón "completas y modernas". ${ }^{10}$

El testimonio de Flores y Troncoso se confirma al leerse la introducción del Tratado elemental de histología, del doctor J. A. Fort, catedrático libre de anatomía en la Escuela Práctica de París. Ahí se dice que no es una obra original y que, si bien contiene las observaciones del autor, se han incluido también la de otros "microscopistas" tanto de origen francés como alemán, con la intención de crear un compendio que sirviera de texto para que los alumnos de medicina se adentraran en el saber histológico. ${ }^{11}$

Al tomar en cuenta el periodo histórico en el que se desarrolla la teoría celular en Europa y el desarrollo histórico de las disciplinas en las que dicha teoría se fue recibiendo, desarrollando y difundiendo en México, se puede elaborar una primera hipótesis de trabajo sobre las fuentes en las cuales es posible seguir la recepción de la teoría en cuestión.

Dos grupos documentales parecen conformar el acervo que debe ser revisado, por un lado, las tesis de medicina $y$, por otro, las publicaciones médicas periódicas, dentro de estas últimas es que se inscribe la Gaceta de la Academia Nacional de Medicina de México, pues a pesar de que no se trata de una publicación especializada en los campos de la histología o la anatomía patológica, si es, tanto por su antigüedad como por la constancia de su aparición en el tiempo, el grupo documental más antiguo en el que se puede rastrear la recepción de la teoría celular en México.

Con esto en mente se inició una búsqueda en los artículos de carácter histológico publicados en la Gaceta, tratando de rastrear la posible exposición de los fundamentos de la teoría celular, sin embargo, en este grupo prácticamente no existen referencias al respecto, lo más destacable es un trabajo del doctor Miguel Cordero, en el que describe las características morfológicas de la sangre en individuos mexicanos sanos, para lo cual desarrolló, en colaboración con un pintor, un ingenioso aparato "cromométrico" que le permitía medir la coloración normal de los eritrocitos e inferir a partir de ahí su contenido de hemoglobina. ${ }^{12}$

Posteriormente se revisaron los trabajos de anatomía patológica; en estos, de una u otra forma, se encuentra la totalidad de referencias a la teoría celular contenidas en la Gaceta en el siglo XIX. Los trabajos que remiten a dicha teoría constituyen un conjunto pequeño de artículos publicados a lo largo del siglo XIX. Desde un punto de vista cuantitativo son superados con creces por los artículos dedicados a cuestiones de aplicación práctica, como los métodos diagnósticos en clínica, los tratamientos, tanto farmacológicos como quirúrgicos, o por disciplinas como la sanidad pública y la microbiología; esta última, por la magnitud y el impacto de sus resultados, era muy atractiva para los investigadores de la época.

Dentro de este pequeño conjunto son escasas las referencias a los estudios histológicos antes de la década de los ochenta, entre las pocas se encuentra un trabajo publicado por el doctor Luis Hidalgo y Carpio en 1864, que apareció en Gaceta Médica de México con el título genérico de "Anatomía patológica".

En ese trabajo, el doctor Hidalgo y Carpio presentó el estudio de un caso: un paciente de 50 años sin ningún antecedente de patología ósea a quien fue necesario amputarle el miembro inferior izquierdo. De acuerdo con la descripción, sobre la extremidad libre del hueso del muñón había periostio, el canal medular adelgazado se había extendido a dicho punto de la extremidad, conteniendo médula ósea "y encima un tejido celular condensado sobre el que reposaba la cicatriz". ${ }^{13}$

Después de haber hecho la descripción macroscópica de la lesión y de describir los procedimientos quirúrgicos realizados en el paciente, el doctor Hidalgo y Carpio afirmó que lo presentaba por ser un caso atípico de cicatrización y agregó:

[...] además de que sirve para confirmar la opinión histológica de que el tejido medular contribuye tanto como el periostio y el cartílago, al desarrollo del tejido huesoso, sea transformándose, según unos, directamente sea secretando, según otros, un blastema en medio del cual se forma aquel. ${ }^{13}$

Todo parece indicar que esta es la primera mención a la teoría celular publicada en México, a poco mas de dos décadas de que Schleiden y Schwann describieran el citoblastema, que en términos generales fue concebido por dichos investigadores como una especie de gelatina formada a partir de moco, almidón y goma, sobre la cual emergían pequeños núcleos en torno a los cuales se formaba el núcleo celular, luego, mediante un proceso del que si bien se desconocían sus detalles específicos se le suponía de origen químico, y se le atribuía la capacidad de transformar dicha gelatina en una sutil vesícula que se adaptaba al citoblasto, a la manera en que lo hace el vidrio a la carátula de un reloj, para formar así una célula nueva $^{9}$

El trabajo del doctor Hidalgo y Carpio carece de aparato crítico, por lo que no es posible precisar a 
qué fuentes hace referencia cuando habla de la hipótesis histológica, hoy carente de toda validez, que pretendía explicar la formación del tejido óseo a partir de la participación del periostio, el cartílago y la médula ósea. Sin embargo, es clara la mención que hace a la teoría del citoblastema y a la polémica científica que se había generado a su alrededor, pues las observaciones de Schwann de las células de la notocorda habían dejado clara la existencia de un citoblastema animal, semejante al que Schleiden había identificado en el desarrollo de las células vegetales, que además de encontrar un elemento común entre los dos reinos permitió que se aceptara la idea de la existencia de un órgano con vida propia constitutivo de los animales, idea que se oponía a la noción vitalista de la existencia de una fuerza que produciría las transformaciones que irían moldeando al animal.

El trabajo en cuestión tampoco incluye ninguna descripción microscópica, y si bien lo que pretende probar a través de la observación macroscópica es la participación de la médula ósea en la formación del tejido óseo, la referencia a la teoría celular pareciera insertarse únicamente para mostrar que se conocen los pormenores de la misma, manteniéndose la discusión exclusivamente en un plano teórico.

Los demás artículos que componen el conjunto de trabajos en el que hay referencias a la teoría celular fueron publicados en las últimas dos décadas del siglo XIX, lo que coincide con el periodo de institucionalización de la disciplina histológica en México; a continuación se describen los que resultan de mayor interés para comprender el proceso de recepción de dicha teoría.

En 1880, el doctor Adrián Segura publicó sus consideraciones sobre la patogenia de las neoplasias, trabajo en el que revisa la clasificación que dividía dichas entidades, de acuerdo con criterios morfológicos, en homólogas y heterólogas, por un lado, y en homeomorfas y heteromorfas, por otro, para, tras enunciar el omnis cellula e cellula virchowniano, adherirse a la clasificación de este autor que las atribuía bien sea a una heterotopía, a una heterocronía o a una heterometría. ${ }^{14}$

El trabajo pasa enseguida a plantear la siguiente pregunta, que de acuerdo con el doctor Segura era de interés tanto para los histólogos como para los clínicos de la época: ¿Los tumores son manifestaciones de un estado general, o bien se trata primitivamente de alteraciones locales que infectaban después a la economía? Aclara que la primera premisa de la pregunta era sostenida por Billroth, mientras que la segunda por Virchow. Frente a tal disyuntiva, y careciendo de estudios histológicos, el doctor Segura, con base en su experiencia clínica, opta por una postura ecléctica. ${ }^{14}$ Luego expone las explicaciones que apoyaban la teoría de la generalización del proceso local a través de tres mecanismos posibles: la transformación de los tejidos inmediatos a la neoplasia por acción transformadora de esta, la diseminación a través de la vía linfática y la diseminación por la vía hematógena.

También parte de su experiencia para oponer las siguientes objeciones a las hipótesis anteriores, en cuanto al primer mecanismo considera que faltan pruebas que evidenciaran dicha transformación y aseguren que la misma no se producía sobre células que ya estaban enfermas, aunque de un modo latente. Mientras que para objetar los otros dos mecanismos se basaba en las observaciones de otros autores que habían fracasado al intentar diseminar un tumor inyectando sus células en cualquiera de las vías en cuestión en animales de experimentación. ${ }^{14}$

Para ahondar en la comprensión del proceso, mediante el que se podría explicar a la sazón la generalización de la neoplasia, el doctor Segura se remonta a la definición general de la vida que Comte había formulado a partir de las ideas de Blainville, definiéndola como "un movimiento general y continuo de composición y descomposición de los seres organizados, colocados en el medio apropiado", ${ }^{14}$ a partir de esta describe el ciclo vital de la célula, para posteriormente, con ciertos resabios humoralistas, definir la salud como el equilibrio entre los procesos de composición y los de descomposición y a la enfermedad como su desequilibrio.

Posteriormente, basándose siempre en esta teoría, el doctor Segura construye desde un punto de vista lógico las posibles combinaciones entre los procesos de composición y los de descomposición, mismos que expresa en los siguientes términos:

Este desequilibrio puede consistir en un aumento de la composición, quedando igual la descomposición; $2^{\circ}$ en una disminución de la composición, con una descomposición normal; $3^{\circ}$ en una composición normal, un aumento en la descomposición, y por último, una disminución en la descomposición con normal composición. Por consiguiente, en el primero y en el último caso, aumentan los productos de la nutrición, mientras que en los dos intermedios disminuirán. ${ }^{14}$

Finalmente, ubica a las neoplasias dentro del cuadro construido, sosteniendo que se generan debido al aumento de los elementos morfológicos al tiempo que disminuye su desasimilación, lo que de acuerdo con él quedaba probado por "[...] las innumerables 
celdillas que proliferan, ya sea por endogénesis, ya por fisiparidad; (y) [...] porque se observan muy pocas que están en un estado de regresión franca [...]"14

Bajo este orden de ideas sostiene que a mayor desequilibrio mayor gravedad de la neoplasia, y enuncia la ley formulada por Waldeyer, misma que transcribe en los siguientes términos: "una neoplasia es tanto más grave cuanto mayor es el numero de celdillas móviles que tiene y mayor la cantidad de jugos nutritivos que la alimentan", ${ }^{14} \sin$ embargo, no parece distinguir entre el aumento de celdillas en general y el aumento de celdillas "móviles", tal como las que menciona la ley referida por él.

Termina la revisión de los aspectos teóricos sobre la patogenia de las neoplasias mediante el uso de una serie de metáforas, que hacen progresar las nociones de producción y gasto a la producción fabril, a la demanda de profesionistas dentro de una sociedad o a la transformación de un condiloma benigno en un cáncer maligno. ${ }^{14}$

Once años más tarde, el doctor Eduardo Vargas publicó un trabajo que al compararse con los anteriores presenta un manejo del aparato crítico mucho más cercano al aceptado actualmente. Las principales fuentes a las que se refiere son el Tratado de cirugía de Duplay y Reclus y la Patología Quirúrgica de Billroth, entre otras. Para el desarrollo de su argumento se remonta a revisar las doctrinas de Lebert, Broca y Follin, las cuales ubicaba "[...] en la época en que se creía en los blastemas [...] (y no) se sospechaba siquiera entre las celdillas del cáncer y las celdillas normales ninguna analogía", ${ }^{15}$ pues como hemos visto, se consideraba que las células cancerígenas nacían del blastema.

Posteriormente menciona las aportaciones de Müller y de Virchow y de manera muy particular, por la relevancia que tienen para su trabajo, las aportaciones de Robin Carnil y de Waldeyer, para la comprensión del origen epitelial del cáncer, idea que removía la concepción difundida por Virchow respecto a que el cáncer tenía su origen en el tejido conectivo.

Vargas menciona también los trabajos de Malassez, Robin y Rindflesh, como ejemplos de aportaciones recientes que apoyaban el origen epitelial de la enfermedad..$^{15}$

Basándose en la obra de Duplay y Reclus, ofrece la siguiente descripción de la demostración anatomopatológica:

[...] los tumores descritos con el nombre de carcinoma alveolares no son sino epiteliomas difusos y que en una misma pieza anatómica se pueden encontrar todas las transiciones entre una neoformación claramente epitelial y las formas más típicas del carcinoma. Los ejemplos son frecuentes en la glándula mamaria y son también claros en otros parénquimas. ${ }^{15}$

Los elementos de la teoría celular expuestos en este articulo permiten al doctor Eduardo Vargas interpretar un caso clínico en el que el paciente presentaba una neoplasia difusa y maligna en el hueco de la axila y un epitelioma superficial en el hueco de la mano, que le fue diagnosticada como "úlcera roedora de Hutchinson".

Después de que el doctor Hurtado realizara el estudio histológico, mismo del que se da la descripción completa en el trabajo del doctor Vargas, se llegó a la conclusión de que la neoplasia axilar era secundaria al epitelioma de la mano.

Todo parece indicar que este es el primero de los trabajos publicados en la Gaceta que se acompaña del estudio microscópico en el que, si bien su autor está al tanto de diversos aspectos conceptuales propios de la teoría celular, deja atrás las generalidades de la especulación filosófica para centrarse en la revisión histórica de los aspectos específicos que le permitían construir un marco teórico en el que se insertaban sus contribuciones diagnósticas.

Los últimos trabajos del siglo XIX en los que se puede rastrear la recepción de la teoría celular en la Gaceta Médica de México fueron publicados por el doctor Manuel Toussaint, en ellos resalta inmediatamente la acuciosidad de su formación como anatomo-patólogo adquirida tras su estancia en Europa.

Como ejemplo de lo antes expuesto tomaremos su contribución al estudio anatomo-patológico del cilindroma, trabajo en el que justificaba los estudios histopatológicos por considerarlos para el histopatólogo como:

[...] la única base cierta en que puede apoyarse para hacer una clasificación científica de dichas lesiones y determinar sus límites respecto a las demás entidades nosológicas; e interesa también al clínico porque le permite adelantarse de una manera increíble en el diagnóstico y el tratamiento de las mismas. ${ }^{16}$

Destacaba, además, la importancia de haber aplicado la teoría celular al estudio de las neoplasias, en particular en lo que respecta a su caracterización y clasificación, recordaba al respecto las aportaciones de Muller, Virchow y, particularmente, las de Thiersch, quien al comprobar "[...] el origen del cáncer epitelial siempre en el epitelio, un nuevo factor se introdujo, y la división en tumores epiteliales y tumores conjuntivos se impuso[...]", ${ }^{16}$ destacando con ello la distinción entre carcinomas y sarcomas.

Aclaraba también cómo el trabajo del detalle histológico, aunado a la definición del cuadro clínico 
correspondiente a las diversas especies neoplásicas, realizada por los cirujanos, había terminado por imponer un criterio morfológico al concepto de malignidad, que consideraba que "[...] los tumores cuya estructura no reproduce la de algún tejido bien formado [...]"16 eran los que deberían de ser considerados malignos.

El objetivo del trabajo era muy claro, se trataba de contribuir a la definición de la estirpe celular que daba origen al cilindroma, para ello hace una revisión teórica que deja de lado los aspectos generales para centrarse específicamente en las descripciones del cilindroma, desde la primera descripción realizada por Billroth en 1864 y pasando por las contribuciones de Koester, Rustitzky, Ewetsky, Friedlaender, Kocher, Sattler. Entre los autores franceses incluye a Cornil, Ranvier, Malassez, y también incorpora en la revisión las aportaciones de Kolaczec, Ackerman, Klebs, Fischer, Braun, von Ohlen y Marchand.

El meollo de la estirpe celular era que los autores franceses consideraban al cilindroma como un tipo de epitelioma, mientras que los otros autores citados dividían su opinión, pues para algunos se trataba de un sarcoma, mientras que para otros debía de ser un endotelioma.

Aunado al problema de su origen celular se encontraba también la cuestión referente al punto de partida de la degeneración hialina. El doctor Toussaint decidió hacer a un lado los aspectos químicos de dicho problema, para centrarse en su aspecto histológico.

Al revisar los aspectos teóricos de la degeneración hialina menciona que Tommasi, Friedreich, Stender y Koester hacían derivar los cilindros o cordones homogéneos "[...] de las mismas celdillas y esto por razón de encontrar en el seno de las masas hialinas algunas veces elementos celulares bien constituidos", ${ }^{16}$ mientras que Billroth, Foerster, Sattler y Kocher, que habían señalado la presencia de vasos ocupando el centro de algunos cilindros, "ven en la degeneración de la adventicia el origen de estos". ${ }^{16}$

Finalmente, menciona que Friedlaender y Ewetsky, entre otros, consideraban que la alteración se localizaba en el estroma conjuntivo o que por lo menos ahí comenzaba y era donde predominaba. Luego expone los detalles de los cuatro casos que él había podido estudiar, y con base en las observaciones ahí descritas concluye:

1. Que en los casos de cilindroma que me ha sido dado examinar microscópicamente, dicho tumor puede ser clasificado como endotelioma.

2. Que la comparación con algunas especies de endotelioma apoya esa manera de ver.
3. Que, en los mismos casos por mi observados, la degeneración hialina comenzó por el tejido conjuntivo y atacó a éste de preferencia. ${ }^{16}$

Queda claro que tanto por la especificidad del aparato crítico, como por el estudio microscópico de los cuatro casos, y particularmente por las aportaciones hechas al campo de conocimiento de la anatomo-patología del cilindroma, este trabajo del doctor Manuel Toussaint constituye un bello ejemplo de quehacer científico en el que la recepción de la teoría celular, por parte de alguien que dominaba tanto el campo teórico como las cuestiones técnicas, no se inscribía en su repetición erudita, sino que permitía su verificación a través de observaciones originales que ponían a prueba los enunciados constituyentes de dicha teoría.

\section{Discusión y conclusiones}

Como se ha mencionado, la revisión de los artículos publicados en la Gaceta Médica de México no agota el tema de la recepción de la teoría celular en nuestro país, pero aporta algunos datos para la comprensión de un proceso histórico que por necesidad es más complejo, pero que permite hasta aquí extraer algunas conclusiones parciales.

En primer lugar, este análisis ha permitido identificar los nombres de algunos médicos que participaron en el proceso de recepción de la teoría celular, lo que abre la posibilidad de identificar, por un lado, la movilidad laboral de dichos sujetos a través de distintas instituciones, que contribuirá a una mejor comprensión del proceso histórico al eliminar divisiones artificiales introducidas desde el presente.

Por cuestiones de espacio no es posible extenderse en el análisis, pero es pertinente señalar que los autores aquí presentados simultáneamente fueron miembros de la Academia Nacional de Medicina, profesores en la Escuela Nacional de Medicina, algunos se incorporaron a los Institutos, como el doctor Manuel Toussaint, en el Instituto Patológico Nacional, y otros, como el doctor Adrián Segura, combinaron su trabajo médico con el quehacer político. ${ }^{1}$

Por otro lado, el mismo listado de nombres permite identificar la actividad clínica preponderante de cada uno de los médicos, siempre y cuando se tenga cuidado de no introducir, nuevamente aquí, otra división desde el presente emanada de la actual estructura de las especialidades médicas, permite agrupar tal actividad dentro de los dos grupos principales en los que se dividió el quehacer médico en el siglo XIX, es decir, el clínico y el quirúrgico. 
Sí además se toma en cuenta, que el proceso de recepción de cualquier teoría es un proceso activo que termina en cada momento en una publicación, es posible darse cuenta de que en la recepción de la teoría celular en los trabajos publicados en Gaceta Médica de México, los cirujanos desempeñan un papel preponderante en el periodo previo a su institucionalización y a la profesionalización de la histopatología en nuestro medio.

Lo anterior, aunado a la revisión del aparato crítico de los artículos que cuentan con él, también permite afirmar que los textos quirúrgicos de la época desempeñaron un papel central en el proceso de recepción de dicha teoría, siendo en algunos casos más relevantes que el texto de Virchow, autor que hasta antes del presente estudio era considerado el principal referente, sino el único, en la historiografía médica mexicana. La importancia de tal figura no queda en duda, siempre y cuando se considere que en el proceso de recepción de la teoría celular en México, sus observaciones fueron ponderadas al lado de las recabadas en los grandes tratados quirúrgicos de la época, como el de Bilroth, Duplay y Reclus, y el de Kocher, entre otros.

Desde el trabajo clásico de Owsei Temkin, Metaphors of Human Biology, se abrió la posibilidad de analizar las metáforas en biología y su correlato histórico. La teoría celular no estuvo exenta de ser portadora de metáforas que tuvieron un impacto más allá del campo médico-biológico insertándose en el campo político, particularmente por la mediación de los trabajos de Virchow. Estas metáforas fueron también recibidas en México, como lo prueban los enunciados de orden sociopolítico presentes en el trabajo del doctor Adrián Segura, sin embargo, por la complejidad inherente, el análisis a profundidad de dichos enunciados se deja para otro momento. ${ }^{17}$

Otra aportación del presente análisis es que ha permitido identificar al menos dos momentos en la historia de la recepción de la teoría celular en México. El primero en el que la recepción es exclusivamente teórica y su concreción da cuenta de una forma más o menos erudita de los conocimientos que tal o cual autor tiene de las generalidades de la teoría celular. $Y$ un segundo periodo en donde el conocimiento de la teoría celular se acompaña del manejo de las técnicas histológicas y de una metodología teórica, que deja de lado en su exposición los aspectos generales de la teoría, para presentar la revisión histórica de series pertinentes de hechos biológicos, que justifican la investigación que en su momento se estaba llevando a cabo y sobre los cuales se anclaban los resultados obtenidos.
Siendo en el segundo tipo de trabajos en los que la relación entre la teoría científica justifica los procedimientos técnicos, cuya aplicación, a su vez, afianza, corrige, o francamente desecha algunos aspectos de la teoría, estableciendo entre técnica y teoría, un diálogo fecundo en el cual se percibe el desarrollo completo del campo disciplinar en cuestión. En nuestro caso son los trabajos de los doctores Eduardo Vargas y Manuel Toussaint los que corresponderían a esta etapa, mismos que en el tiempo coinciden con el momento de desarrollo institucional de la histología y de la histopatología en México, disciplinas fundamentadas en la teoría celular.

Finalmente, dado que lo que se aborda aquí es una parte del proceso histórico de la recepción de la teoría celular, vigente hoy en día y herramienta teórica dentro de las ciencias médico-biológicas, es pertinente señalar que cuando dicha teoría deja de ser una herramienta conceptual para ser tomada como objeto de estudio, bien sea desde una perspectiva histórica o desde el ámbito de la reflexión filosófica, el desplazamiento de la herramienta teórica a objeto de estudio inscribe la teoría biológica en el ámbito propio de las humanidades médicas, lo que exige un abordaje metodológico e interpretativo propio de estas últimas.

\section{Bibliografía}

1. Fernández-Del Castillo F. Historia de la Academia Nacional de Medicina de México. México: Fournier; 1956

2. Erhmann C, Jiménez M. Prospecto. Gac Med Mex.1864;1:1-3.

3. S/A, Introducción. Gac Med Mex. 1874;9(1):2.

4. Hinke N. El Instituto Médico Nacional: la política de las plantas y laboratorios a fines del siglo XIX. México: Universidad Nacional Autónoma de México/Centro de Investigación y Estudios Avanzados del IPN; 2012.

5. Castañeda LG. Bosquejo histórico del Museo Anatomopatológico, 18951899. An Med (Mex). 2009:54(1):52-56.

6. Cuevas-Cárdona C. Ciencia de punta en el Instituto Bacteriológico Nacional (1905-1921). H Mex. 2007;57(1):53-89.

7. Rodríguez-Pérez ME. La Academia Nacional de Medicina de México (1836-1912). Gac Med Mex. 2013;149:569-575.

8. Cházaro-García L. Introducción. En: Hinke N. El Instituto Médico Nacional: La política de las plantas y laboratorios a fines del siglo XIX. México: Universidad Nacional Autónoma de México/Centro de Investigación y Estudios Avanzados del IPN; 2012.

9. Albarracín-Teulón A. La teoría celular. España: Alianza Universidad; 1983.

10. Flores-Troncoso FA. Historia de la medicina en México. Edición facsimilar, Tomo III. México: Instituto Mexicano del Seguro Social; 1982.

11. Fort JA. Traité élémentaire d'histologie. France: Adrien delahaye libraire-éditeur; 1873

12. Cordero M. Estudio anatómico de la sangre en los individuos sanos de México. Gac Med Mex. 1884;19:425-469.

13. Hidalgo-Carpio L. Anatomía Patológica. Gac Med Mex.1864;1:64.

14. Segura A. Breves consideraciones acerca de la patogenia de las neoplasias, sobre todo las cancerosas y su tratamiento. Gac Med Mex. 1880;15:417-431.

15. Vargas E. Algunas consideraciones acerca de la posibilidad de una infección secundaria de los ganglios linfáticos, manifestándose en ellos como carcinoma, y teniendo como punto de partida la preexistencia de un epitelioma situado a distancia. Gac Med Mex. 1891;26(1):7-11.

16. Toussaint M. Contribución al estudio anatomo-patológico del cilindroma Gac Med Mex. 1894:31:430-441.

17. Owsei T. The double face of janus and other essays in the history of medicine. EE. UU.: The Johns Hopkins University Press; 1977. 